\title{
Çocuklarda Trakeabronşial Yabancı Cisim Aspirasyonları
}

\section{Tracheabronchial Foreign Body Aspirations in Children}

Burhan Apilioğulları ${ }^{1}$,

Gürcan Koşal' ${ }^{1}$,

Sami Ceran ${ }^{1}$.

Ahmet Dumanlı²

${ }^{1}$ Necmettin Erbakan Üniversitesi, Meram Tıp Fakültesi, Göğüs Cerrahisi Anabilim Dalı, Konya Türkiye

${ }^{2}$ Afyon Kocatepe Üniversitesi, Tıp Fakültesi, Göğüs Cerrahisi Anabilim Dalı, Konya,

Türkiye

Kabul Tarihi/Accepted: 20 Temmuz 2019

Yazışma Adresi: Burhan Apilioğulları, Necmettin Erbakan Üniversitesi, Meram Tıp Fakültesi, Göğüs Cerrahisi Anabilim Dalı, Konya,Türkiye

e mail: bapiliogullari@yahoo.com

\section{ORCID}

Burhan Apilioğulları

https://orcid.org/0000-0001-8257-7847

Gürcan Koşal

https://orcid.org/0000-0002-1415-1155

Sami Ceran

https://orcid.org/0000-0003-1596-0760

Ahmet Dumanlı

https://orcid.org/0000-0002-5768-7830
Geliş Tarihi/Received: 18 Aralık 2018

\begin{abstract}
Öz
Amaç: Yabancı cisim aspirasyonu (YCA) pediatrik yaş grubunda sık görülen ciddi bir sorundur. Tanı ve müdahale de gecikme hayatı tehdit eden bir duruma neden olabilir. Biz bu çalışmamızda kliniğimizde YCA tanısı almış ve tedavisi yapılmış olan hastaların dosya verilerini değerlendirmeyi amaçladık.

Hastalar ve Yöntem: Kliniğimizde 2014-2017 yılları arasında müdahale edilen 47 hastayı retrospektif olarak, başvuru anındaki klinik semptomu, yaş, cinsiyet, yabancı cismin (YC) natürü, yerleşim yeri, pozitif radyolojik bulgu ile hastaneye başvuru zamanı olarak inceledik.

Bulgular: 47 hastanın; 29 erkek (\%63), 18 kadındı (\%37), yaşları 3 ay ile 8 yaş arasında değişmekteydi. 37 hastanın yaşı (\%80) 3 yaşın altındaydı. Hastaların başvuru anında asıl șikayet olarak, 37'nde öksürük (\%80), 23 hastada hırıltılı solunum (\%50), 15 hastada nefes darlığı (\%32,6), 5 hastada geçmeyen enfeksiyon $(\% 10,8), 2$ hastada yüksek ateş $(\% 4,3)$ vardı. 37 hastada $(\% 78)$ çıkartılan yabancı cisim organik kökenli (çekirdek içi veya kabuğu, fıstık, fındık parçaları ve benzeri) iken 10 hastada (\%22) inorganik yabancı cisime rastlandı (kalem ucu, oyuncak parçası, sibop, plastik parçalar gibi.). YC 18 hastada (\%39) sağ ana bronşta, 25 hastada $(\% 51)$ sol ana bronşta, 4 hastada $(8,7)$ ise trakeada yerleşmişti. 18 hastanın (\%39) radyolojik olarak herhangi bir bulgusu yoktu, 11 hastada $(\% 23,9)$ anamnez mevcut ancak göğüs muayenesinde dinleme bulgusu normaldi, 23 hasta olay olduktan sonraki ilk 24 saat içinde kliniğimize başvurmuşken, 24 hasta olay olduktan sonraki 24 saati geçen zaman diliminde kliniğimize başvurmuştu. Sonuç: YCA'ya maruz kalmış hastanın tanıdan hemen sonra, rijit bronkoskopi imkânının bulunduğu bir hastaneye zaman kaybetmeden sevk edilmesi hayati önem taşımaktadır. Çalışmamızın sonuçları genel olarak literatüre uyumlu olmakla beraber, YC yerleşim yeri açısından \%51 ile sol ana bronşun öne çıkmasıyla literatürden farklılık gösterdi.
\end{abstract}

Anahtar Kelimeler: Yabancı cisim, trakeobronşial aspirasyon, bronkoskopi

\section{Abstract}

Aim: Foreign body aspiration (FBA) is a serious problem frequently seen in the pediatric age group. Delay in diagnosis and intervention can cause a life-threatening situation. In this study, we aimed to evaluate the files of patients diagnosed with FBA in our clinic and treated.

Patients and Method: We retrospectively evaluated 47 patients who were treated in our clinic such as clinical symptoms, age, gender, foreign body (FB), location, positive radiological findings, and duration of stay between 2014-2017.

Results: 47 patients; 29 male $(63 \%)$, 18 female $(37 \%)$, age ranging from 3 months to 8 years. The age of the 37 patients $(80 \%)$ was below the age of 3 years. The main complaint at the time of admission was cough $(80 \%)$ in 37 patients, wheezing in 23 patients $(50 \%)$, shortness of breath in 15 patients $(32.6 \%)$, infection in 5 patients $(10.8 \%)$, high in 2 patients. there was fever $(4.3 \%)$. In 37 patients $(78 \%)$, the foreign body was of organic origin (such as inside or outside the shell, peanuts, hazelnut pieces) while in 10 patients $(22 \%)$, an inorganic foreign object was found (such as a pen tip, a toy part, plastic parts, etc.). FB was located in the right main bronchus in 18 patients (39\%), in the left main bronchus in 25 patients $(51 \%)$ and in the trachea in 4 patients $(8.7)$. There were no radiological findings in 18 patients $(39 \%)$. Although 11 patients $(23.9 \%)$ were anamnesis, their findings were normal. Twenty-three patients applied to our clinic within the first 24 hours after the event, and 24 patients were admitted to our clinic 24 hours after the event.

Conclusion: It is of vital importance that the patient is referred to a hospital where a rigid bronchoscopy can be performed quickly after the diagnosis. Although the results were generally consistent with the literature, the left main bronchus was $51 \%$ in terms of the localization of FB.

Key words: Foreign body, tracheobronchial aspiration, bronchoscopy

Atıf yapmak için: Apilioğulları B, Koşal G, Ceran S, Dumanlı A. Çocuklarda Trakeabronşial Yabancı Cisim Aspirasyonları. Selcuk Med J 2020;36(3): 238-243 


\section{GíRiş}

Yabancı cisim aspirasyonu (YCA) karşılaşılmak istenmeyen en ve ne yazık ki sonucu oldukça kötü olabilen bir durumdur. Böyle bir durumda karşılaşan kişiler genellikle ne yapacağını bilememekte doğal bir panik hali yaşamakta ve dakikaların hayati öneme sahip olduğu bu anların gereksizce harcanmasına neden olabilmektedir. YBC özellikle 3 yaş altı çocuklarda görülmektedir. Erken tanı ve hızlı tedavi, YCA ile ilişkili komplikasyonları ve mortaliteyi azaltmanın en önemli yoludur. Anamnez bize yardımcı olan en önemli etkenlerdendir. Unutulmamalıdır ki klinik ve radyolojik bulguların normal olması YCA tanısını ekarte ettirmez $(1,2)$. Şüpheli olgularda bronkoskopi ile kontrolün yapılması gerekmektedir. Erken müdahale edilebilen vakalarda, YCA'nın neden olabileceği hava yolu inflamasyonu, hemoptizi, bronşektazi, pulmoner atelektazi, hatta asfiksi ve ölüm gibi ciddi komplikasyonlar engellenebilmektedir (3). Çocuklarda aspire edilen yabancı cisimler genellikle çekirdekiçi, fıstık, gıda ve oyuncak parçalarını içerir (4). Ani başlayan öksürük ve boğulma hissi en sık görülen semptomlardır (5).

Biz bu çalışmamızda kliniğimizde YCA tanısı almış ve tedavisi yapılmış olan hastaların dosya verilerini değerlendirmeyi amaçladık.

\section{HASTALAR VE YÖNTEM}

Kliniğimizde 2014-2017 yılları arasında YCA şüphesiyle başvuran ve yapılan bronkoskopi sonucu YC tespit edilen 47 hastayı retrospektif olarak değerlendirdik. YCA şüphesi nedeniyle başvuran, yapılan bronkoskopi sonucu normal çıkan herhangi bir YC tespit edilmeyen hastaları değerlendirme dışında bıraktık. YC çıkan hastaların; başvuru anındaki klinik semptomu, yaş, cinsiyet, yabancı cisimin (YC) natürü, yerşelim yeri, pozitif radyolojik bulgular, olay anı ile hastaneye başvurduğu zaman arasında geçen süre incelendi. Hastaların tamamında yabancı cisim çıkartılma işlemini rijit bronkoskopi ile sağladık. YC tespit etmede ve lokalizasyonunu belirlemede 0 derece ve 30 derece optik görüntüleme sisteminden yararlandık. 6 aydan küçüklerde 2,5-3 mm, 6 ay ile 12 ay arasındaki hastalarda $3,5 \mathrm{~mm}, 12$ ay ile 24 ay arasındaki hastalarda 3,5-4 mm, 2 yaşından büyük hastalarda $4 \mathrm{~mm}$ çaplı rijit bronkoskopi cihazını kullandık. İşlemin hepsi genel anestezi altında yapıldı. İşlem öncesinde aileye işlemin gerekliliği, nasıl yapılacağı ve oluşabilecek komplikasyonlar hakkında yeterli bilgilendirme sağlandı. Yazılı olarak ayrıntıı onam kağıdı alındı.

\section{BULGULAR}

47 hastanın; 29'uerkek (\%63), 18'i kadındı (\%37), yaşları 3 ay ile 8 yaş arasında değişmekteydi. 37 hastanın yaşı (\%80) 3 yaşın altındaydı. Hastaların başvuru anında asıl şikayet olarak, 37'sinde öksürük (\%80), 17 hastada $(\% 36,9)$ morarma, 23 hastada hırıltılı solunum (\%50), 15 hastada nefes darlığı (\%32,6), 5 hastada geçmeyen enfeksiyon (\%10,8), 2 hastada yüksek ateş $(\% 4,3)$ vardı. 37 hastada $(\% 78)$ çıkartılan yabancı cisim organik kökenli (çekirdek içi veye kabuğu, fıstık, fındık parçaları gibi) iken 10 hastada (\%22) inorganik yabancı cisime rastlandı (kalem ucu, oyuncak parçası, plastik parçalar gibi). YC 18 hastada (\%39) sağ ana bronşta, 25 hastada (\%51) sol ana bronşta, 4 hastada $(8,7)$ ise trakeada yerleşmişti. 18 hastanın (\%39) radyolojik olarak herhangi bir bulgusu yoktu, 11 hastanın $(23,9)$ ise anamnez olmasına rağmen göğüs muayenesinde dinleme bulgusu normaldi, 23 hasta olay olduktan sonraki ilk 24 saat içinde kliniğimize başvurmuşken, 24 hasta olay olduktan sonraki 24 saati geçen zaman diliminde kliniğimize başvurmuştur.

(Tablo 1)

\section{TARTIŞMA}

Trakeobronşiyal YCA çocuklarda özellikle 3 yaş altı çocuklarda daha sık görülmektedir (6). Bu yaş grubundaki çocuklarda kaza ile olan ölümlerin en sık dördüncü nedenidir (7). Bizim çalışmamızda literatür ile uyumlu çıkmıştır. Ekip olarak bize ilginç gelen durum ise en küçük hastamızın 3 aylık olmasıdır. Ailelerin YCA konusunda bilinçlendirilmesi gerektiğini düşünüyoruz.

Çevreye karşı artan ilgi, nöromuskuler mekanizmaların yeterince gelişmemiş olması nedeniyle yetersiz hava yolu koruma refleksi, zayıf çiğneme kabiliyeti, molar dişlerinin olmaması, çiğneme işleminin efektif yapılamaması, ağlarken yemek yeme gibi etkenler özellikle 3 yaş altı çocuklarda YCA yüksek olmasının başlıca nedenleridir (8). Ancak bazı durumlarda yetişkinlerde de ortaya çıkabilir. Yemek yerken gülme, bilinç bozukluğu, nöromuskuler hastalıklar ve cisimleri ağızda tutma alışkanlığı gibi nedenler erişkinlerdeki yabancı cisim aspirasyonları arsında sayılabilir. Farhad B. et al (9) tarafından yapılan bir çalışmada, (en sık mı?) çocuklarda yaşamın ikinci yılında, erişkin grubunda ise altıncı dekatta meydana geldiği bildirilmektedir.

\section{Tanı}

YCA'na maruz kalan bir hastada ne yazık ki bulgular 
Tablo 1. Yabancı Cisim aspirasyonu Sonuçları

\begin{tabular}{lll}
\hline Yaş & 3 ay -8 yaş & $37(\% 80)$ \\
Cinsiyet & 3 yaş ve altı & $29(\% 63)$ \\
& Erkek & $18(\% 37)$ \\
Şikayet & Kadın & $37(\% 80)$ \\
& Öksürük & $17(\% 36,9)$ \\
& Morarma & $23(\% 50)$ \\
& Hırıltılı solunum & $15(\% 32,6)$ \\
& Nefes darlığı & $5(\% 10,8)$ \\
Dinleme bulgusu & Geçmeyen enfeksiyon & $2(\% 4,3)$ \\
& Yüksek ateş & $16(\% 34)$ \\
Radyolojik bulgu & Solunum sesi azalmış & $24(\% 51)$ \\
& Wheezing & $1(\% 02)$ \\
Stridor & $11(\% 23,9)$ \\
Nerleşim yeri & Normal & $2(\% 04)$ \\
& Atelektazi & $1(\% 02)$ \\
Başvuru süresi & Pnömonik infiltrasyon & $18(\% 39)$ \\
& Normal AC grafisi & $30(\% 63)$
\end{tabular}

nonspesifik olabilmektedir. Anamnezin dışındaki diğer bulgular bize YCA tanısına yönlendirmeyebilir ve kesin tanı koymak zorlaşabilmektedir. Öksürük ilk olarak karşımıza çıkabilen ve en sık rastlanan bulgulardır. Bizim çalışmamızda da şikayet oranlarına bakıldığı zaman \%80 ile öksürük ilk sırada yer almaktadır. Başlarda nöbetler halinde gelen, spazmodik, kuru, irritatif olan öksürük, yabancı cisim bronşa yerleştikten sonra şiddetini ve özelliğini kaybeder $(10,11)$. Boğulma hissi ve siyanoz diğer sık rastlanan bulgulardandır. Fizik muayene bulguları olarak, ateş, wheezing, stridor, retraksiyonlar ve tek veya çift taraflı olarak azalmış solunum sesleri karşımıza çıkabilir (12). Oskültasyonda tespit edilen anormal solunum seslerinin YCA'nun en yaygın işareti olduğunu, öksürük, ateş, dispne ve boğulmanın izlediğini literatürdeki meta analizler belirtmektediri (13). Özellikle yemek sırasında başlayan öksürükle beraber ses çıkartılamaması, nefes almada zorluk ve morarma bize YCA olabileceğini düşündürmesi gerekir (düşündürmelidir). Olay henüz yeni olmuş ve akut safhada ise özellikle öksürük, boğulma hissi, morarma anamnezde ön plana çıkmaktadır. Aileler bu safhada yabancı cismi teyit edebilirler. Yabancı cismin boyutuna, yerleştiği bölgeye göre fizik muayene bulguları farklılık gösterebilir. Trakeadaki YC tıkanıklığın derecesine göre, öksürük, hırıltılı solunum, stridor, dispne ye neden olabilirler. Ne yazık ki epiglot bölgesindeki tam tıkanıklıklar ölümle sonuçlanabilmektedir. Unutulmaması gereken bir diğer önemli nokta ise, hastanın başvuru esnasında klinik bulgularının olamayabileceğidir. Daha distale ilerleyerek yerleşen yabancı cisimler hiçbir bulgu vermeyebilir ve zamanla tahrişe ve ödeme neden olabilir. Bize başvuran ve YC çıkartılan hastaların \%23'ün dinleme bulgusu normal olarak bulunmuş herhangi bir ek yada patolojik dinleme bulgusu tespit edilmemiştir. YC'nin uzun süre kalması, solunum mukozasında erozyona ve hemoptiziye neden olabilir. Olay daha da uzarsa bronşların kronik obstrüksiyonu tekrarlayan pnömoni ve bronşektaziye neden olabilir (14).

YCA'dan şüphelenilen hastalarda radyolojik incelemeler mutlaka yapılmalıdır. Radyoopak olan cisimlerin tespiti yapılabilir (Şekil 1). Radyoopak olan olmayan cisimler ise görülemeyebilir. Yapılan çalışmalarda aspire edilen yabancı cisimlerin \%90'ının radyo opak olmadığı tespit edilmiştir (1). Hava giriş çıkışına izin veren YC'lerin ise normal havalanma şeklinde görüntü verebileceği unutulmamalıdır. Normal bir göğüs radyografisi YCA tanısını ekarte ettirmez, şüphe devam ediyorsa mutlaka bronkoskopi yapılmalıdır $(10,11)$. Fasulye, nohut gibi şişme potansiyeline sahip cisimlerde başvuru esnasında ciddi semptom bulunmasa bile zamanla organik cismin şişerek totoal tıkanıklığa neden olabileceği 


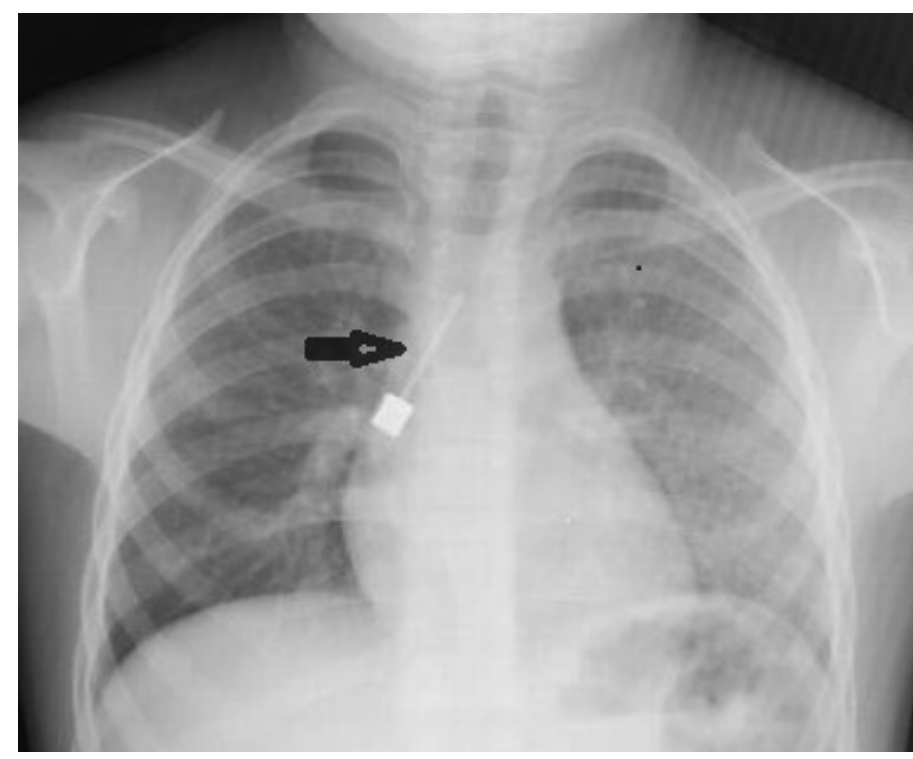

Şekil 1. Sağ ana bronşa yerleşmiş radyoopak yabancı cisim (sibop)

unutulmamalıdır (Şekil 2). Şişme potansiyeli bulunan cisim aspirasyonu anamnezi olan hastalarda beklenmeden bronkoskopi yapılmalıdır. YCA olduğu kanıtlanan olguların \%24-30'unda direk göğüs radyografisi normal olarak değerlendirildiğini bildiren çalışmalar mevcuttur $(1,2)$. Bizim çalışmamızda bu oran biraz daha yüksek \%39 oarak bulunmuştur. Bazı yayınlarda toraksın bilgisayarlı tomografik

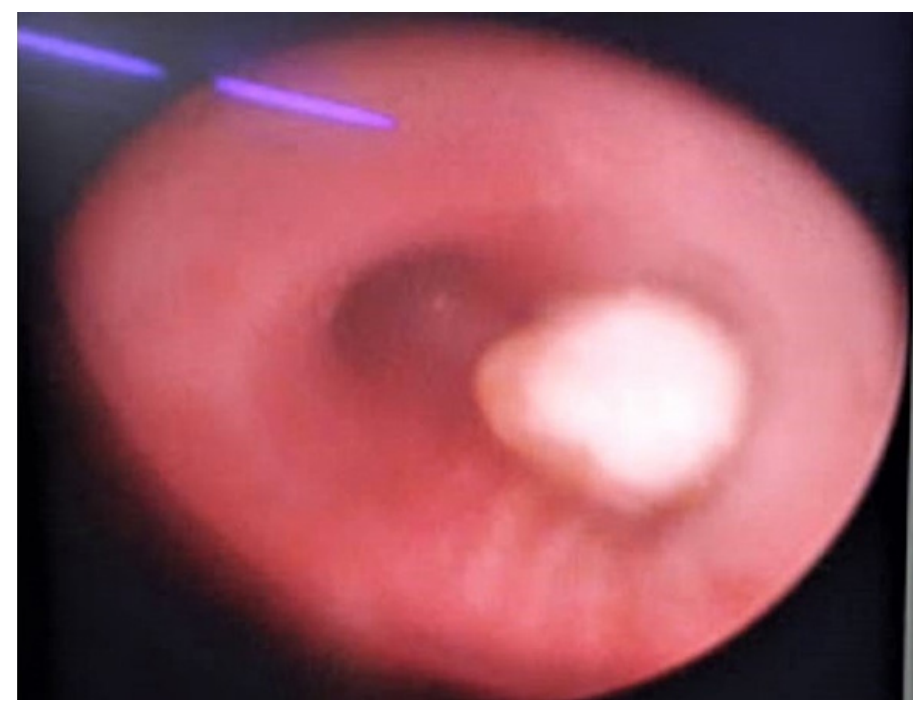

Şekil 2. Sağ ana bronşu şişerek tamamen tıkamış organik yabancı cisim (fasülye) incelemesinin, göğüs grafisine testine göre YCA'ler için tanıda daha iyi bir duyarlılık ve özgüllük gösterdiği bildirilmiştir (3).

YC'ler literatüre bakıldığında çoğunlukla sağ ana bronş yerleşimli olduğu görülmektedir. Bizim çalışmamı ise YC yerleşim yeri açısından \%51 ile sol ana bronşun öne çıkmasıyla literatürden farklılık gösterdi. Sağ ana bronşun sola kıyasla daha geniş açı yaparak sanki trakeanın devamı gibi seyretmesi, buna karşılık sol ana bronşun daha keskin açıya sahip ve çapının daha dar olması ile YC'lerin sağa daha çok kaçma sebebi açıklanmaktadır. 3 yaşının altındaki çocuklarda bu açının henüz çok belirginleşmemiş olması, bizim çalışmamızdaki vakalarda sol ve sağ ana bronş arasında belirgin farkın olmamasını açıklayabilir diye düşünüyoruz.

Radyolusent olan YC'ler çoğunlukla olayın üzerinden 24 saat geçtikten sonra indirekt radyolojik bulgular ile karşımıza çıkarlar. Ana bronşlara yada daha distale oturan YC adeta bir sübap gibi davranarak etkilenen tarafta havanın hapsolmasına neden olabilir. Bu da radyolojik olarak tek taraflı havalanma artışı şeklinde karşımıza çıkabilmektedir. Bizim vakalarımızın \%63 gibi yüksek bir oranında bu radyolojik bulgu tespit edilmiştir. Zamanla hapsolmuş havanın absorbe olmasıyla radyolojik olarak atelektazi bulgusu ile karşılaşılabilir(8). İlave olarak geçikmiş vakalarda pnömoni, bronşektazi ve akciğer absesi bulgularına da rastlanabilmektedir.

\section{Tedavi}

Yapılmaması gereken ancak refleks olarak ilk başvurulan yanlış yöntem, çocuğun ağzına parmak sokarak YC çıkartılmaya çalışılmasıdır. Sokulan parmak büyük oranda $Y C$ çıkartılmasını sağlamadığı gibi, YC'i daha da distale itebilmekte ve tablonun ağırlaşmasına neden olabilmektedir. Özellikle büyük hava yolları tıkanıklıklarında çoğu zaman olay yerinde yapılabilecek işlem Heimlich manevrası olmaktadır. Tam ya da tama yakın tıkanıklığı olan hastalarda, ambu maskesi ventilasyonunun rolünü değerlendiren veriler olmamasına rağmen, ambu maskesi ile ventilasyon bu vakalarda faydalı olabilir. YC distal hava yollarına itebilmesi açısından her ne kadar bir risk varsa da, daha kesin tedaviler denenene kadar hipokseminin ilerlemesini yavaşlatabilir (14). Esnek veya rijit bronkoskopi, hava yolundaki FB'leri uzaklaştırmak için kullanılan ana yöntemdir (15). YC çıkarılması için bronkoskopi seçimi yazarlar arasında farklılık göstermektedir. Bazı ekipler Fleksibl Bronkoskopiyi (FB) tercih ederken, çoğu yazar rijit bronkoskopinin (RB) en iyi prosedür olduğunu düşünmektedir (6). Biz 
de YCA vakalarımızda RB'nin daha etkili olduğunu düşündüğümüz için tercih ediyoruz. Buradaki vakalarımızın hepsine rijit bronkoskopi yöntemini uyguladık. FB ile YC tespit edilse bile, zaten çapı oldukça dar olan bronkoskoptan geçen daha küçük çaplı forceps, çoğu zaman YC’leri çıkartmada yetersiz kalmakta, bronkoskopun içinden çıkartmak mümkün olmadığı için her seferinde FB ile birlikte tamamen çıkmak zorunda kalınması, akabinde işlemin yenilenmesinin gerekmesi, hastanın aynı anda ventile edilememesi gibi faktörler bizim RB'yi tercih etmemizin ana unsurlarındandır. Tam emin olunamayan ve YCA şüphesi düşük olan vakalarda FB'nin ilk olarak uygulanmasının daha doğru olduğu kanaatindeyiz.

Yabancı cismin çıkarılması sırasında karşılaşılması muhtemel komplikasyonları cerrahın göz önünde bulundurması her açıdan faydalı olacaktır. Başlıca karşılaşılabilecek komplikasyonları; bronkospazm, laringospazm, subglottik ödem, laringeal ödem, pnömotoraks, pnömomediastinum, hipoksi, larinks ve trakeabronşial yaralanma, mide içeriğinin aspirasyonu ve arrest olarak sayılabilir. Ayrıca genel anestezinin ve anesteziye bağlı ilaçların komplikasyonu bulunmaktadır. Anestezi ve bronkoskopideki artan tecrübeyle birlikte morbidite ve mortalite oranlarının \%1'in altına düştüğünün yayınlarda bildirilmesi sevindiricidir (10). Ayrıca görülen komplikasyon sıklığı tanı 24 saatten sonra konan olgularda daha da artar, bu nedenle erken tanı ve tedavi önemlidir $(16,17)$. Bronkoskopi işleminde tanıda doğruluk oranının artıııması ve olası komplikasyonların azaltılması amacıyla RB içersinden ilerletilebilen optik görüntüleme sistemlerinden yararlanılması gerektiğini düşünüyoruz. Çalışılan alanın oldukça dar ve küçük olması çıplak gözle çalışmayı ve yanılma oranını artırabilmesinden dolayı optik görüntüleme sistemi cerraha daha iyi bir görüş açısı sağlaması açısından önemlidir. Acil durumlarda anestezi yapılmadan acil bronkoskopi yapılabilir. Bununla birlikte, genel anestezi hastaları bilinçsiz hale getirir, bu da ameliyat için daha güvenli ve uygun kabul edilir. Tedavide Cerrahi nadiren gerekmekte ve son çare olarak uygulanmaktadır. Biz buradaki hiçbir vakamıza cerrahi tedavi uygulamak zorunda kalmadık.

Sonuç olarak belirtmek gerekirse; özellikle 3 yaşın altındaki çocukların YCA açısından risk taşıdıklarının akıldan çıkartılmaması gerekir. YCA'dan şüphelenildiği andan itibaren hastanın mümkün olan en kısa sürede rijit bronkoskopinin yapılabileceği bir merkeze ulaşmasının sağlanması hayati açıdan önem arz etmektedir. Unutulmaması geren bir diğer önemli nokta ise YCA'nun radyolojik bulgu vermeyebileceğidir. Anamnezinde şüphe olan her hasta muayene ve radyolojik bulgusu olmasa bile YBC açısından değerlendirilmelidir. Hatta klinik dinleme bulgusu da olamayabilir. Biz YCA hikayesi ile gelen hastalarımıza radyolojik görüntüler normal olsa dahi şüphe varlığında bronkoskopi öneriyoruz.

Çıkar Çatışması: Çalışmada herhangi bir çıkar çatışması yoktur.

Finansal Çıkar Çatışması: Çalışmada herhangi bir finansal çıkar çatışması yoktur.

Yazışma Adresi: Burhan Apilioğulları, Necmettin Erbakan Üniversitesi, Meram Tıp Fakültesi, Gögüs Cerrahisi Anabilim Dalı, Konya, Türkiye

e-mail: bapiliogullari@yahoo.com

\section{KAYNAKLAR}

1. İlçe Z. Tracheobrobchial foreign body aspiration in children. Medical Journal of Kocaeli 2012;2:47-54.

2. Ikeda M, Himi K, Yamauchi, et al. Use of digital subtraction fluoroscopy do diagnose radiolucent aspirated foreign bodies in infants and children. Int J Pediatr Otorhinolaryngo 2001;61: 233-42.

3. Sahin A, Meteroglu F, Eren S, et al. Inhalation of foreign bodies in children: Experience of 22 years. J Trauma Acute Care Surg 2013;74:658-63.

4. Baram A, Sherzad H, Saeed S, et al. Tracheobronchial foreign bodies in children: The role of emergency rigid bronchoscopy. Global Pediatric Health 2017.(4):p 1-6.

5. Mapelli E, Sabhaney V. Stridor and drooling in infants and children. In: Tintinalli JE, Stapczynski J, Ma O, Yealy DM, Meckler GD, Cline DM, eds. Tintinalli's Emergency Medicine: A Comprehensive Study Guide. 8th ed. New York, NY: McGraw-Hill Education; 2015:chap 123.

6. Boufersaoui A, Smati L, Benhalla KN, et al. Foreign body aspiration in children: Experience from 2624 patients. International Journal of Pediatric Otorhinolaryngology 2013;77:1683-8.

7. Rodríguez H, Passali GC, Gregori D, et al. Management of foreign bodies in the airway and oesophagus. Int J Pediatr Otorhinolaryngol 2012;76:S84-91.

8. Akgül AG. Trakeobronşiyal yabancı cisimler. Yüksel $M$, Eraslan BA, ed. Göğüs Cerrahisi. Nobel Tıp Kitapevi Yayınları, İstanbul, 2015:1085-92.

9. Farhad B, Francis V, Charles F, et al. Tracheobronchial foreign bodies: Presentation and management in children and adults. Chest 1999;115(5):1357-62.

10. Gürsu S, Sırmalı M, Gezer S, et al. Tracheobronchial foreign body aspirations in adults. Turkish J Thorac Cardiovasc Surg 2006;14(1):38-41

11. Erikci V, Karacay S, Arikan A. Foreign body aspiration: A fouryears experience. Ulus Travma Derg 2003;9:45-9.

12. Tomaske M, Gerber AC, Stocker S, et al. Tracheobronchial foreign body aspiration in children - diagnostic value of symptoms and signs. Swiss Med Wkly 2006;136(33-34):5338. 
13. Foltran F, Ballali S, Passali FM, et al. Foreign bodies in the airways: A meta-analysis of published papers.Int J Pediatr Otorhinolaryngol 2012; 76 Suppl 1():S12-9

14. Lowe DA, Vasquez R, Maniaci V. Foreign body aspiration in children. Elsevier 2015;6(3):140-8.

15. Mallick MS. Tracheobronchial foreign body aspiration in children: A continuing diagnostic challenge. Afr J Paediatr Surg 2014;11(3):225-8.
16. Baram A, Sherzad $H$, Saeed $S$, et al. Tracheobronchial foreign bodies in children: The role of emergency rigid bronchoscopy. Global Pediatric Health 2017;4:1-6.

17. Liang J, $\mathrm{Hu} \mathrm{J}$, Chang $\mathrm{H}$, et al. Tracheobronchial foreign bodies in children - a retrospective study of 2,000 cases in Northwestern China. Ther Clin Risk Manag 2015;11:1291-5. 